for the trivalent iodine compound benzene iodo dichloride (angles of $86^{\circ}$ ). The geometry at the iodine is in accord with that found in $\mathrm{BrF}_{3}$ (ref. 7) and $\mathrm{ClF}_{3}$ (ref. 8).

(3) The 11 atoms in the molecule are coplanar within twice the estimated standard deviation of the individual atoms.

(4) By consideration of the angles and distances around $O(3)$, it appears that it is hydrogen bonded to $O(1)$ of a neighbouring molecule. The distance of this hydrogen bond was found to be $2 \cdot 8 \pm 0 \cdot 1 \AA$.

(5) The contact between the iodine of one molecule and $O(3)$ of another molecule related to the first by the screw axis is $2.90 \pm 0.05 \AA$ (Fig. 1). This distance is significantly less than the sum of the van der Waals radii of the two atoms, which is $3 \cdot 6 \AA$. This $\mathrm{O}(3)$ atom is within $0.6 \AA$ of the least squares plane of the first molecule. This type of interaction has been observed in various jodate structures ${ }^{9}$. Trueblood ${ }^{10}$ has suggested that this may be another reflexion of the terdency of the iodine atom to act as a weak Lewis acid, manifested in many polyiodides and other 'complexes'.

This work was supported in part by U.S. Public Health Service grant A-3909 from the National Institute of Arthritis and Metabolic Diseases.

\section{ELI ShefteR}

Department of Chemistry,

University of California,

Los Angeles 24, California.

\section{WALTER WOLF}

School of Pharmacy,

University of Southern California, Los Angeles, California.

' Willgerodt, C., Chem. Ber., 26, 357 (1893).

${ }^{2}$ Askenasy, P., and Meyer, V., Chem. Ber., 26, 1354 (1893).

' Bell, R., and Morgan, K. J., J. Chem. Sce., 1209 (1960).

- Wolf, W, and Hsu, L., Abstr. Papers, 54C, 146th Meeting of Amer. Chem. Soc. (Jan. 1964)

'Pauling, L., The Nature of the Chemical Bond, third ed., 224 (Cornell Univ. Press, Ithaca, New York, 1960).

- Archer, E. M., and Van Schalkwyk, T. G., Acta:Cryst., 6, 88 (1953).

- Magnuson, J., J. Chem. Phys., 27, 223 (1952).

${ }^{8}$ Smith, D. F., J. Chem. Phys., 21, 609 (1953). Burbank, R. D., and Bensey, F., J. Chem. Phy8., 21, 606 (1953).

- Ibers, J. A., Acta Cryst., 8, 225 (1956).

${ }^{10}$ Trueblood, K. N. (personal communication).

\section{Unit Cell and Space Group of $\mathrm{Co}(\text { thiourea })_{4}$. $\left(\mathrm{NO}_{3}\right)_{2}$}

A PRELIMINary X-ray investigation of the crystal of $\mathrm{Co}\left[\mathrm{SC}\left(\mathrm{NH}_{2}\right)\right]_{4}\left(\mathrm{NO}_{3}\right)_{2}$ has been made, using the mothod of Rossenheim and Meyer for preparing the compound. It crystallized as dark blue prisms. The unit cell dimensions of the monoclinic crystal were determined from single crystal rotation and Weissenberg photographs using copper $K \alpha$-radiation.

The values found are: $a=20.31 \AA ; \quad b=16.80 \AA$; $c=11.68 \AA$ (all $\pm 0.03 \AA) ; \beta=91 \cdot 6 \pm 0.2^{\circ} . \quad V=3.984$ $\AA^{3}$. The number of molecules per unit cell is $N=8$; calculated value 8.17 for a density of $1.65 \mathrm{~g} / \mathrm{c} . c$.

Observed extinctions were $h+k$ odd for $h k l$ and $k$ odd and $l$ odd for $h 0 l$ and $k$ odd for $0 k 0$ reflexions, which are consistent with the two space groups, $\mathrm{C}_{s}^{4}-\mathrm{C}_{c}$ and $\mathrm{C}_{z h}^{\prime i}-\mathrm{C}_{2 / c^{\circ}}$.

Statistical determinations of the centre of symmetry by Ramachandran's method showed the presence of centre of symmetry for the projection [001] as required for the group $\mathrm{C}_{2 \hbar}^{6}-\mathrm{C}_{2 / c^{*}}$

\section{Perez Rodriguez \\ M. Cubero \\ M. Garcia Gea}

Division de Ciencias del C.S.I.C.,

Department of Physics,

University of Seville, Spain.

\section{PHYSICS}

\section{Suggested Units for Conductivity}

IN the hybrid system of units most frequently used for electrical conductivity $\sigma$ the units are $\mathrm{ohm}^{-1} \mathrm{~cm}^{-1}$. Often the atrocity $\mathrm{mho} / \mathrm{cm}$ is used and neither form is particularly convenient if it is necessary to specify the units several times in a short space.

After giving due consideration to the disadvantages of introducing still another form of notation into the already overburdened literature, it is felt that the abbreviation 'roc' to stand for reciprocal ohm-centimetre is a worthwhile addition. The M.K.s. form follows, that is,

$$
\sigma[\mathrm{rom}]=100 \sigma[\mathrm{roc}]
$$

\section{R. E. BARKer, JUN.}

General Electric Research Laboratory, Schenectady, New York.

\section{Rapid Non-destructive Analysis of Oxygen by Neutron Activation}

IT is known that in 29.4 sec oxygen-19 is formed by neutron irradiation of natural oxygen and that it emits $0 \cdot 200-\mathrm{MeV} \gamma$-ray. Since the activation cross-section of ${ }^{18} \mathrm{O}(n, \gamma){ }^{19} \mathrm{O}$ and the abundance of oxygen-18 are both low $\left(0.21 \pm 0.04 \mathrm{~m}\right.$ barn ${ }^{1}, 0.204$ per cent $^{1}$, respectively), the activation analysis using oxygen-19 is only applicable to the determination of macro-amounts of oxygen.

A sample is irradiated for $30 \mathrm{sec}$ in a $J R R-1$ reactor at a neutron flux of about $3 \times 10^{11} \mathrm{n} / \mathrm{cm}^{2} / \mathrm{sec}$, cooled for $30 \mathrm{sec}$, counted for $30 \mathrm{sec}$, again cooled for $10 \mathrm{sec}$ and counted for 30 sec. The counter used is a 2 -in. thick $\times$ 1.75-in. diam., well-type sodium iodide crystal attached to an $R C L-256$ channel pulse height analyser. During the counting operation the sample is placed $1 \mathrm{~cm}$ above the crystal. An aluminium disk of $2,150-\mathrm{mg} / \mathrm{cm}^{2}$ thick is used as an absorber for $\beta$-rays from the sample.

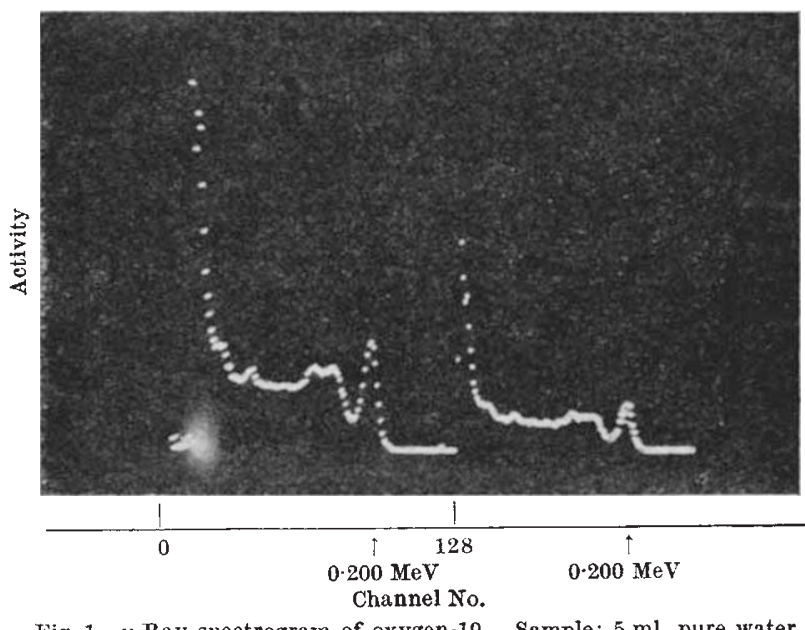

Fig. 1. $\gamma$-Ray spectrogram of oxygen-19. Sample: $5 \mathrm{ml}$. pure water

An example of successive spectra thus obtained is shown in Fig. 1. The decay curve of photopeak due to $0 \cdot 200-\mathrm{MeV} \gamma$-ray is measured at short time-intervals and the half-life is determined as about $30 \mathrm{sec}$. From both $\gamma$-ray energy and half-life, oxygen-19 is identified.

The activation method is applied to the determination of oxygen in organic compound. Pure water is used as an oxygen standard. Oxygen is determined by comparing the peak height of $0 \cdot 200-\mathrm{MeV} \gamma$-ray with that of standard. Some results of analyses by this method are shown in 